\title{
Regulation of Voltage-gated Ion Channels by NGF and Ciliary Neurotrophic Factor in SK-N-SH Neuroblastoma Cells
}

\author{
Steven S. Lesser and Donald C. Lo \\ Department of Neurobiology, Duke University Medical Center, Durham, North Carolina 27710
}

\begin{abstract}
Neurotrophic factors have powerful effects on neuronal differentiation and the maintenance of neuronal phenotype, but understanding of their regulation of one important aspect of neuronal function, excitability, remains limited. We have examined the regulation of voltage-gated ion channels by two unrelated neurotrophic factors, NGF and ciliary neurotrophic factor (CNTF), in the SK-N-SH neuroblastoma cell line that is responsive to both factors. NGF and CNTF have strikingly different neuronal specificities and distributions in the nervous system, and might be expected to have significantly different effects on neuronal function. Using whole-cell, perforated-patch, and single-channel recording, we found that treatment with NGF increased levels of voltage-gated sodium, calcium, and potassium currents. In contrast, CNTF treatment increased levels of potassium currents only. NGF and CNTF appeared to regulate the same delayed-rectifier potassium current; in addition, NGF treatment resulted in increased levels of a second potassium current component. Such differential effects of neurotrophic factors on the expression of voltage-gated ion channels would have profound effects on the excitability of target neurons in vivo.

[Key words: NGF, ciliary neurotrophic factor, sodium channels, calcium channels, potassium channels, neuroblastoma, neurotrophic factors, patch clamping, ion channel regulation]
\end{abstract}

Patterns of expression of different neurotrophic factors in the nervous system overlap significantly, yet these distributions are unique for each factor (see, e.g., Maisonpierre et al., 1990). Since neurotrophic factors, in turn, affect expression of genes important for the function of differentiated neurons (for review, see Hefti et al., 1993), the differential regulation of particular aspects of neuronal function by different neurotrophic factors may be a means by which multiple cellular interactions control neuronal phenotype. Properties such as excitability and synaptic transmission, in particular, must be well regulated to match the function of a given neuron and its interactions with other neurons in neural circuitry. In this context, we have studied how the two unrelated neurotrophic factors, nerve growth factor (NGF) and ciliary neurotrophic factor (CNTF), regulate voltage-gated ion

\footnotetext{
Received Mar. 8, 1994; revised June 13, 1994; accepted June 16, 1994.

We are grateful to George Augustine, Peter Reinhart, and Nina Tang for their critical reading of the manuscript. We also thank Regeneron Pharmaceuticals for their generous provision of BDNF and CNTF. This work was supported in part by a Klingenstein Fellowship Award in the Neurosciences to D.C.L.

Correspondence should be addressed to Donald C. Lo at the above address.

Copyright (c) 1995 Society for Neuroscience $0270-6474 / 95 / 150253-09 \$ 05.00 / 0$
}

channels in a neuronal cell line, SK-N-SH cells, that responds to both factors.

NGF, the best-characterized neurotrophic factor, is now known to be a member of a family of structurally and functionally related neurotrophins, including brain-derived neurotrophic factor (BDNF), neurotrophin-3 (NT-3), and NT4/5 (for review, see Chao, 1992b). In contrast, CNTF is a member of a structurally related family of cytokines that have been termed "neuropoietic" cytokines or "neurokines" because of their effects on neuronal cell differentiation and function (Saadat et al., 1989; Bazan, 1991; Hall and Rao, 1992; Ip and Yancopoulos, 1992; Manthorpe et al., 1993; Patterson and Nawa, 1993). The role of CNTF in neuronal development and function is particularly interesting as its $\alpha$-receptor component is expressed in highly localized regions throughout the CNS and PNS (Stockli et al., 1989; Davis et al., 1991; Ip et al., 1993). Moreover, the receptor complex for CNTF shares receptor components with the interleukin-6 and leukemia inhibitory factor/cholinergic differentiation factor (IIF/CDF) receptor complexes, suggesting overlapping action of these factors upon neurons expressing only a limited number of receptor subunits. In fact, two of the subunits in the trimeric CNTF receptor complex can form functional receptors for LIF/CDF (Ip et al., 1992, 1993; Davis and Yancopoulos, 1993; Davis et al., 1993a,b). In contrast to high-affinity neurotrophin receptors, which include members of the $t r k$ family of receptor tyrosine kinases, the receptor complex for CNTF does not have any known catalytic activity and most likely interacts with cytoplasmic signaling molecules including the Jak-Tyk family of nonreceptor tyrosine kinases (Ip and Yancopoulos, 1992; Stahl and Yancopoulos, 1993; Stahl et al., 1994). Thus, the initial steps of signal transduction for NGF and CNTF are quite distinct. Together with their differing neuronal specificitics (scc, c.g., Chao, 1992a,b; Ip et al., 1993; Lindsay et al., 1994), this suggests that these two classes of neurotrophic factors may have very different effects on fundamental neuronal properties such as excitability.

We report here that voltage-gated ion channels are differentially regulated by NGF and CNTF in the neuronal cell line SK$\mathrm{N}-\mathrm{SH}$. These cells were originally derived from a human neuroblastoma of presumed sympathetic origin (Biedler et al., 1973, 1978). SK-N-SH cells and subcloned derivatives such as SHSY5Y cells have been studied extensively as models for neuronal differentiation, which can be induced by phorbol esters and retinoic acid (RA; Pahlman et al., 1990; Morton et al., 1992); the actions of these differentiative agents are, in fact, reminiscent of those of neurotrophic factors (for review, see Pahlman et al., 1990). Using whole-cell and perforated-patch recording, we found that NGF regulates levels of voltage-gated sodium, calcium, and 
A

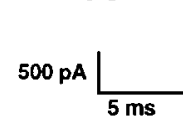

$5 \mathrm{~ms}$

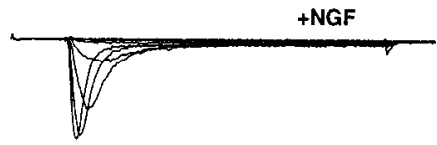

$125 \mathrm{pA} \underbrace{\bigsqcup_{(}}_{25 \mathrm{~ms}}$

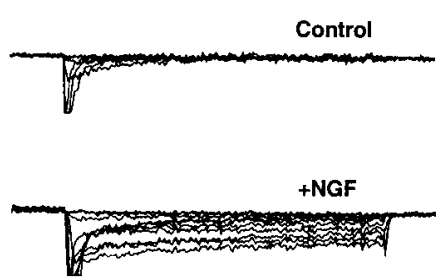

B

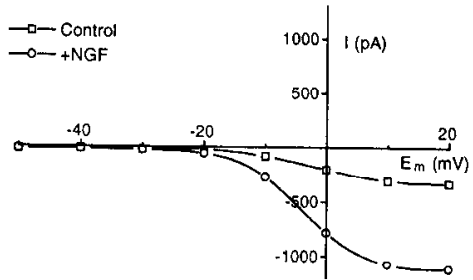

D

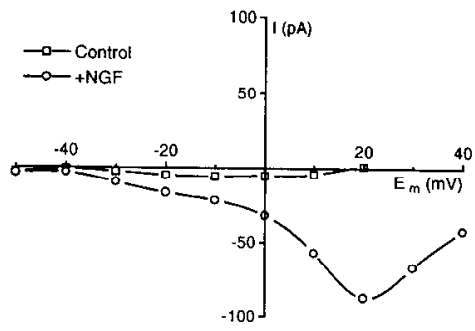

Figure 1. NGF treatment increases sodium and calcium currents in SK-N-SH cells. $A$, Representative whole-cell sodium currents showing increased expression of sodium currents (bottom) compared to control currents (top) induced by treatment with NGF. Cells were held at $-70 \mathrm{mV}$ and wholeccll currents elicited by depolarizing voltage steps to -50 to $+20 \mathrm{mV}$ in $10 \mathrm{mV}$ increments following a $3.2 \mathrm{msec}$ prepulse to $-120 \mathrm{mV}$. Recordings were made with $\mathrm{Cs}^{+}$in the patch pipette to block potassium currents; data were sampled at $10 \mathrm{kHz}$. B, Peak current-voltage relations for the traces in $A$, showing that NGF-induced sodium currents exhibited similar voltage dependence of activation to those expressed in control cells. $C$, Representative whole-cell calcium currents showing increased expression of calcium currents (bottom) compared to control currents (top) induced by treatment with NGF. At this time scale, calcium currents appear as sustained currents that do not inactivate appreciably during the depolarizing pulse, while sodium currents inactivate within $5 \mathrm{msec}$ and are truncated in this figure for clarity. Cells were held at $-70 \mathrm{mV}$ and whole-cell currents were elicited by depolarizing voltage steps to -50 to $+40 \mathrm{mV}$ in $10 \mathrm{mV}$ increments following a $16 \mathrm{msec}$ prepulse to $-120 \mathrm{mV}$; data were sampled at $2 \mathrm{kHz}$. $D$, Steady-state current-voltage relations for the traces shown in $C$ measured $60 \mathrm{msec}$ after the beginning of the voltage step.

potassium currents, but that CNTF regulates potassium current levels only. A common delayed-rectifier type polassium current appears to be regulated by both NGF and CNTF, representing the first description, to our knowledge, of the regulation of potassium currents by individual trophic factors. Finally, using single-channel recording techniques, we identified a potassium channel species that may underlie this delayed-rectifier current.

\section{Materials and Methods}

Cell culture. SK-N-SH human neuroblastoma cells (ATCC) were grown at $37^{\circ} \mathrm{C}$ under $5 \% \mathrm{CO}_{2}$ in RPMI medium supplemented with $10 \%$ fetal bovine serum, $100 \mathrm{U} / \mathrm{ml}$ penicillin-streptomycin, and $2 \mathrm{~mm} \mathrm{~L}$-glutamine in plastic culture flasks (Corning); all media components were purchased from GIBCO-Bethesda Research Labs. Cells to be used in electrophysiological studies were plated onto $35 \mathrm{~mm}$ petri dishes (Corning) and factors were added to a final concentration of $100 \mathrm{ng} / \mathrm{ml}$ for NGF (Collaborative Biochemical), brain-derived neurotrophic factor (BDNF), and CNTF (generously provided by Regeneron Pharmaceuticals, Inc.); RA was added to $30 \mu \mathrm{M}$ and TPA to $20 \mathrm{nM}$ (Sigma). Cells were plated at least $3 \mathrm{~d}$ prior to electrophysiological recording; cultures were fed with fresh medium and factors on day 4 after plating. Since there were no significant differences in whole-cell sodium, calcium, and potassium currents after day 3 , all recordings made after this time were included in our final analysis.

Electrophysiology. Data included in this study were recorded from over 300 cells. Patch electrodes were pulled from borosilicate microcapillary tubes (Drummond), coated with Sylgard elastomer (Dow Corning), and fire-polished. The final resistance of patch electrodes was regularly between 1.5-2.5 M . Whole-cell and outside-out single-channel rccordings werc madc using standard techniques (Hamill et al., 1981), using an Axopatch 1-D patch-clamp amplifier (Axon Instruments). Software written in-house in Visual Basic (Microsoft; with hardware drivers written by INDEC Corp.) was used to acquire data via an optically isolated A/D converter (INDEC). Data were subsequently analyzed using software written in-house and ORIGIN (MicroCal Software). Series resistance and whole-cell capacitance were compensated manually on the patch clamp with subsequent digital leak subtraction. Series resis- tance was typically $<10 \mathrm{M} \Omega$ and whole-cell capacitance was between 8 and $14 \mathrm{pF}$. Since the addition of NGF and CNTF did not significantly change cell capacitance, and cell capacitance did not appear to correlate with the magnitude of ionic currents, data are presented here as absolute currents (see Results). Single delayed-rectifier channel currents were recorded from outside-out patches; single-channel conductances were estimated by linear least-squares fits to current-voltage relations constructed from unitary current amplitudes measured between -30 and $+50 \mathrm{mV}$. Data were recorded at sample intervals of 100 or $500 \mu \mathrm{sec}$, and filtered at $5 \mathrm{kHz}$ for whole-cell recordings and $2 \mathrm{kHz}$ for singlechannel recordings.

Sodium and calcium currents were recorded using a saline containing (in mM) $130 \mathrm{NaCl}, 2 \mathrm{MgCl}_{2}, 10 \mathrm{CaCl}_{2}$, and 10 HEPES (pH 7.4). An internal cesium solution was used to block potassium currents, containing (in mM) $128 \mathrm{CsCl}, 2 \mathrm{MgCl}_{2}, 1 \mathrm{CaCl}_{2}, 11$ EGTA, and 5 HEPES (pH 7.2 with $\mathrm{CsOH}$ ). Sodium and calcium currents could be distinguished unambiguously by their kinetics: sodium channels peaked and then rapidly inactivated within $5 \mathrm{msec}$ of the start of stimulation, while calcium currents increased over 15-20 msec and did not inactivate substantially over $100 \mathrm{msec}$; moreover, sodium current magnitudes were generally several times those of calcium currents. Thus, close estimates for peak sodium and calcium currents could be made from the same sets of traces. We verified the accuracy of calcium current measurements by using prepulse voltage-inactivation paradigms and $4 \mu \mathrm{M}$ TTX to block sodium currents. A portion of the cells included in the sodium and calcium channel study were examined by a perforated-patch recording (Horn and Marty, 1988); for these recordings amphotericin B (Sigma) was added to the internal solution to a final concentration of $0.24 \mathrm{mg} / \mathrm{ml}$. Series resistance for these cells was consistently between 10 and $30 \mathrm{M} \Omega$, and recordings typically reflected good voltage clamping. In most cases, perforated-patch recordings were subsequently "blown out" into the whole-cell recording configuration to confirm the accuracy of recordings. Since we did not observe significant differences between peak sodium and calcium currents measured with the perforated-patch technique compared to whole-cell recording, measurements made using perforated-patch recording were included in our analysis.

Potassium currents were examined using a sodium-free $N$ - methylglucamine (NMG) external solution containing (in mM) $145 \mathrm{NMG}, 2.8$ $\mathrm{KCl}, 2 \mathrm{MgCl}_{2}, 2 \mathrm{CaCl}_{2}$, and 10 HEPES (pH 7.4). For these recordings, the internal solution contained (in $\mathrm{mm}$ ) $140 \mathrm{KCl}, 2 \mathrm{MgCl}_{2}, 1 \mathrm{CaCl}_{2}, 11$ 
EGTA, and 5 HEPES (pH 7.2). Different stimulation paradigms and the pharmacological blockers tetraethylammonium chloride (TEA) and 4-aminopyridine (4-AP; Sigma) were used to separate potassium current components (sce Results).

\section{Results}

\section{Induction of sodium currents}

Treatment with NGF $(100 \mathrm{ng} / \mathrm{ml})$ led to significant increases in the magnitude of sodium currents expressed in SK-N-SH cells (2.2-fold on average, $p<5 \times 10^{-8}$ by ANOVA, $n=40$; Figs. $1 A, 2 A)$. In contrast, CNTF treatment did not increase sodium current levels ( $p>0.15$; Fig. 2A). The induction of sodium currents by NGF appeared to be specific among neurotrophins, as treatment with the related neurotrophin brain-derived neurotrophic factor (BDNF) did not result in significant changes in sodium current levels ( $p>0.8$; Fig. $2 A$ ). NGF addition increased sodium current levels after $2 \mathrm{~d}$, but its effects became most pronounced after $3-4 \mathrm{~d}$ of treatment. Treatment with both CNTF and NGF (100 $\mathrm{ng} / \mathrm{ml}$ of each factor) increased sodium currents to levels indistinguishable from those induced by NGF alone $(p>0.55)$. Sodium currents expressed in SK-N-SH cells exhibited fast activation and fast inactivation typical of mammalian neurons, rising to peak and inactivating completely within $5 \mathrm{msec}$ (Fig. 14). Activation of sodium currents for both control cells and cells treated with NGF first appeared after voltage steps to $-20 \mathrm{mV}$ from a $-120 \mathrm{mV}$ prepulse, with peak currents activated by steps to between +10 and $+20 \mathrm{mV}$. Overall, both control and NGF-treated cells exhibited similar current-voltage relationships (Fig. $1 A, B$ ). Increased sodium current in NGF-treated cells was not associated with changes in cell capacitance $\left(C_{m}\right)$, as we did not observe significant differences among cells in control, NGF-treated, and CNTF-treated groups: $C_{m}=14.0 \pm 3.9$ (mean + SD) for NGF-treated cells, $n=11$; $C_{m}=11.0 \pm 4.0$ for control cells, $n=16$; and $C_{m}=9.1 \pm 2.5$ for CNTF-treated cells, $n=7$. Since no significant changes in cell capacitance were observed in any experimental group, the changes in ionic current levels reported here reflect changes in current density; thus, for simplicity, we have presented the data in terms of absolute current levels.

Treatments with the phorbol ester 12-O-tetradecanoylphorbol-13-acetate (TPA) and retinoic acid (RA) were also examined for effects on ionic current levels in SK-N-SH cells. Although both TPA and RA regulate the expression of proteins important for neuronal function (e.g., neurotransmitter synthesis; see Pahlman et al., 1990), only TPA had a significant effect on current expression in the SK-N-SH cells, leading to increases in sodium currents that were smaller than those induced by NGF (1.5fold, $p<0.05$; Fig. $2 A$ ). The kinetic properties and voltagedependence of sodium currents in TPA-treated cells were indistinguishable from currents in control and NGF-treated cells. Treatment with RA did not lead to significant changes in peak sodium current ( $p>0.55$; Fig. 2).

\section{Induction of calcium currents}

Single sets of current recordings afforded measurements of both sodium and calcium channel currents in the same cells because these currents have very different kinetics. Sodium channels activate and inactivate rapidly and completely within $5 \mathrm{msec}$ (Fig. 1 $A$ ), while the predominant calcium currents in SK-N-SH cells activate more slowly and inactivate only minimally over tens of milliseconds; consequently, little calcium current is activated by the time of peak for sodium currents (Fig. $1 C$ ). More-
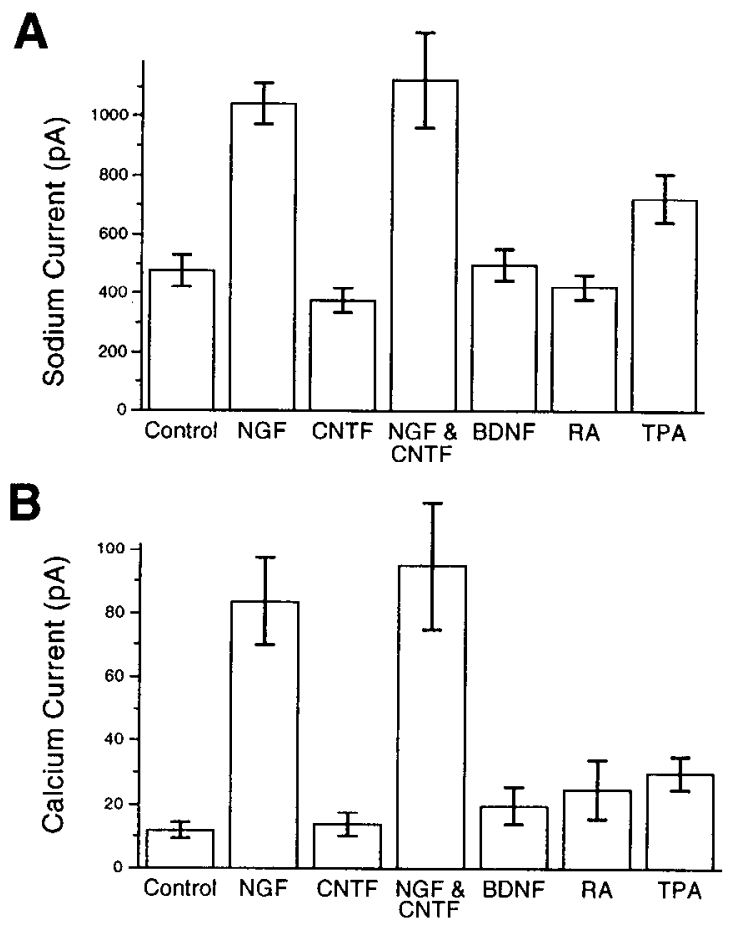

Figure 2. Induction of sodium and calcium currents by NGF and TPA. $A$, NGF and TPA treatment significantly increased sodium currents, while treatment with CNTF, BDNF, and RA had no significant effect; bars represent mean peak sodium currents \pm SEM (Control, $n=38$; $N G F, n=47 ; C N T F, n=23 ; N G F$ and $C N T F, n=22 ; B D N F, n=16$; $R A, n=12 ; T P A, n=14)$. Sodium currents in cells treated with both NGF and CNTF were not significantly different from those treated with NGF alone. $B$, NGF and TPA treatment also significantly increased calcium currents, while CNTF, BDNF, and RA treatments had no significant effect; bars represent mean calcium current measured $60 \mathrm{msec}$ after depolarization \pm SEM. (Control, $n=36 ; N G F, n=47$; CNTF, $n$ $=24 ; N G F$ and $C N T F, n=22 ; B D N F, n=15 ; R A, n=12 ; T P A, n=$ 14). Calcium currents in cells that were treated with both NGF and CNTF were not significantly different from those treated with NGF alone.

over, peak sodium current levels were generally much larger than peak calcium current levels. Thus, we could measure peak amplitudes for both sodium and calcium currents with sufficient accuracy for this study by measuring current levels at different times after depolarization (at $<2 \mathrm{msec}$ for sodium currents and $60 \mathrm{msec}$ after the beginning of the voltage step for the data presented below). We confirmed the accuracy of our calcium current measurements by comparing them to those taken after pharmacological block of sodium currents by TTX (data not shown).

Calcium current levels increased by 7.2-fold in SK-N-SH cells after treatment with NGF ( $p<5 \times 10^{-5}$ by ANOVA, $\left.n=47\right)$. Increases in calcium current could be observed as early as $2 \mathrm{~d}$ after addition of NGF, but became more pronounced after day 4 of treatment (Figs. 1C,D;2B). Induced calcium currents were predominately high threshold and noninactivating [high-voltage-activated (HVA) type; Fig. $1 C, D$ ], with only modest increases in low-threshold, transient calcium currents [low-voltage-activated (LVA) type]. Although the calcium currents reported here contained both of these classes of calcium currents, the majority of the calcium current measured was carried by an HVA-type current; we have therefore focused this study on the HVA calcium current component. While all control cells had measurable 


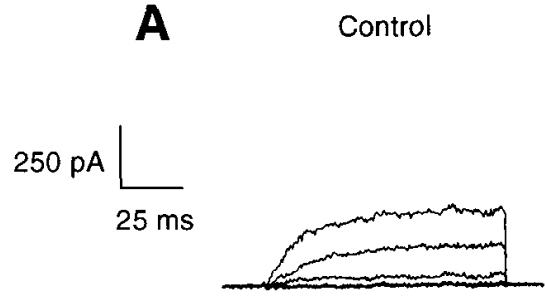

+ TEA

\section{B}
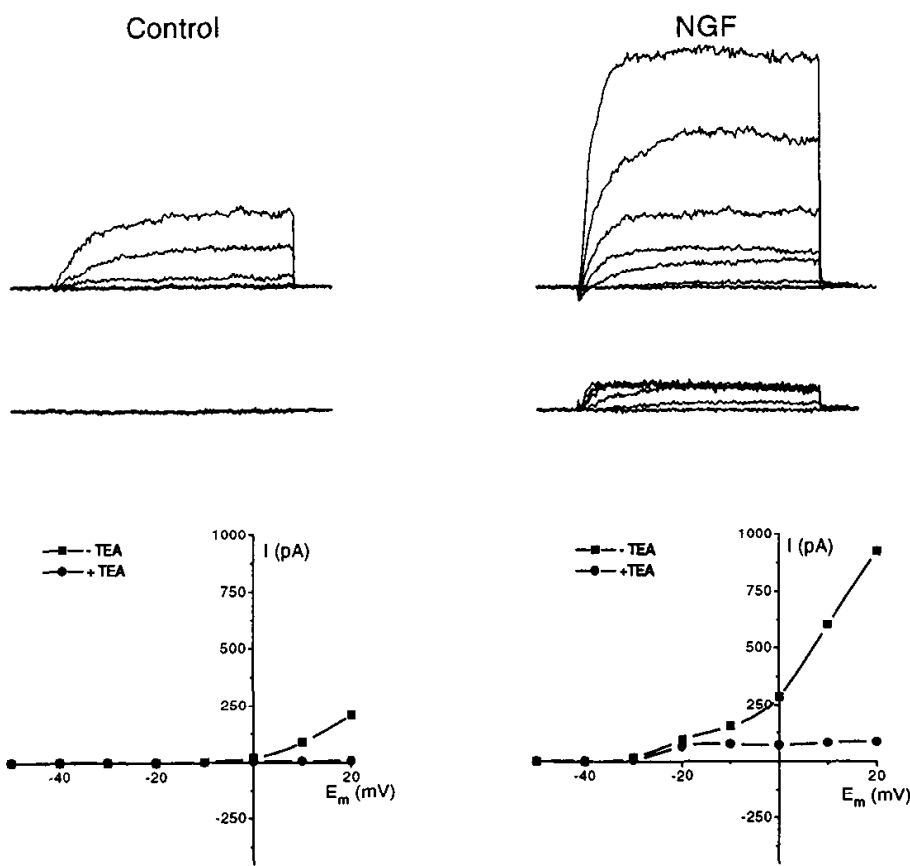

CNTF
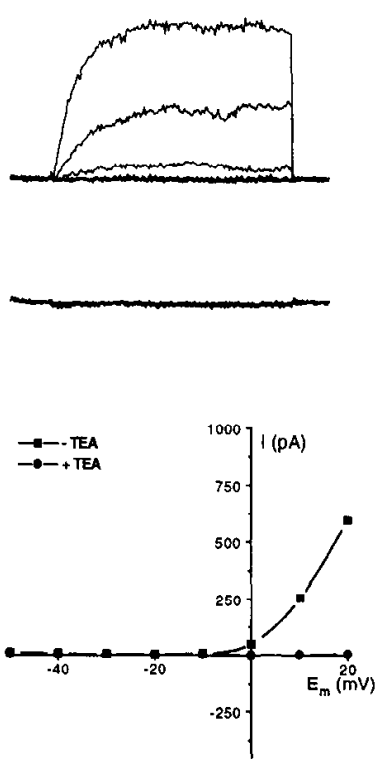

Figure 3. Both NGF and CNTF increase potassium currents. A, Representative whole-cell potassium currents recorded from control, NGF-, and CNTF-treated cells as indicated, before (top) and after block by 5 mM TEA (bottom). Currents in NGF-treated cells contained a small component that was TEA insensitive, while currents in control and CNTF-treated cells were blocked completely by TEA. Potassium currents were elicited by depolarizing voltage steps to -50 to $+20 \mathrm{mV}$ in $10 \mathrm{mV}$ increments following a 16 msec prepulse to $-120 \mathrm{mV}$; holding potential was $-70 \mathrm{mV}$. Sodium and calcium currents were minimized by using a sodium-free, low-calcium external solution. $B$, Current-voltage relations from the traces shown in $A$. An additional potassium current component induced by NGF appears as a "bump" in the current-voltage curve between - 20 and 0 $\mathrm{mV}$ that is more apparent after TEA block.

sodium currents, most control cells had negligible calcium currents $(58 \%$ with less than $5 \mathrm{pA}$ of peak calcium current; e.g., see Fig. $1 C$ ); peak calcium currents in control cells never exceeded $50 \mathrm{pA}$. In contrast, only a small proportion of NGFtreated cells did not have measurable calcium currents $(<15 \%)$, with the majority exhibiting currents exceeding $50 \mathrm{pA}(57 \%$; e.g., see Fig. $1 C$ ). Neither BDNF nor CNTF affected calcium current levels $(p>0.1$ and $p>0.6$, respectively; Fig. $2 B$ ). Addition of CNTF and NGF in combination resulted in calcium current levels indistinguishable from those induced by treatment with NGF alone ( $p>0.6$; Fig. $2 B$ ). As in the case for sodium channels, TPA-treated cells showed modest increases in calcium current levels that were smaller than those induced by NGF ( $p$ $<0.001)$, while RA treatment had no significant effect $(p>$ 0.05 ; Fig. $2 B$ ).

To determine if calcium channel washout (Byerly and Hagiwara, 1982) was affecting our current measurements, we examined 45 cells using perforated-patch recording (Horn and Marty, 1988). Perforated patches are permeable to monovalent cations and chloride ions but not to divalent ions and cellular macromolecules; perforated-patch recording can thus protect against calcium channel washout by minimizing dialysis of molecules important for maintaining calcium channel activity. Most of these cells were subsequently "blown out" into the whole cell recording configuration to allow comparisons between perforated-patch and whole-cell recordings in the same cells. These measurements confirmed that the time course for calcium washout was slow compared to the duration of our recordings, and that washout did not result in significant underestimation of calcium current levels. Additionally, we did not find any evi- dence that calcium current washout occurred at different rates in different experimental groups, arguing against the possibility that the larger calcium currents in NGF- and TPA-treated cells reflected slower, less-significant washout of calcium currents.

\section{Potassium channel regulation}

In contrast to sodium and calcium currents, potassium current levels were increased by both NGF and CNTF in SK-N-SH cells (Figs. 3, 4). Control cells exhibited potassium currents that were first activated by voltage steps to between -10 and $0 \mathrm{mV}$ and exhibited linear current-voltage relationships at voltages above $+20 \mathrm{mV}$, suggesting maximal activation after this point (Fig. 3). These potassium currents activated with kinetics that were well fitted by single exponential functions did not appear to inactivate appreciably over $100 \mathrm{msec}$, and were blocked completely by $5 \mathrm{~mm}$ tetraethylammonium (TEA; Fig. 3) and by 1 mM 4-aminopyridine (4-AP; data not shown). Thus, potassium currents in untreated cells appeared to be predominately of a single, delayed-rectifier type.

The principal effect of CNTF appeared to be the enhancement of this potassium current already expressed at basal levels by control cells (by 2.1 -fold at $+20 \mathrm{mV}, p<0.005$ by ANOVA, $n=31$; Figs. 3,4 ). Potassium currents in CNTF-treated cells exhibited similar current-voltage relations and activation kinetics well fitted by single exponentials, and were blocked completely by $5 \mathrm{~mm}$ TEA (Fig. 3) and $1 \mathrm{~mm}$ 4-AP (data not shown). Potassium currents were also increased in NGF-treated cells (by 2.8 -fold at $+20 \mathrm{mV}, p<5 \times 10^{-6}, n=36$ ) but contained an extra current component not seen in CNTF-treated or control cells. This current component was first activated by voltage steps 


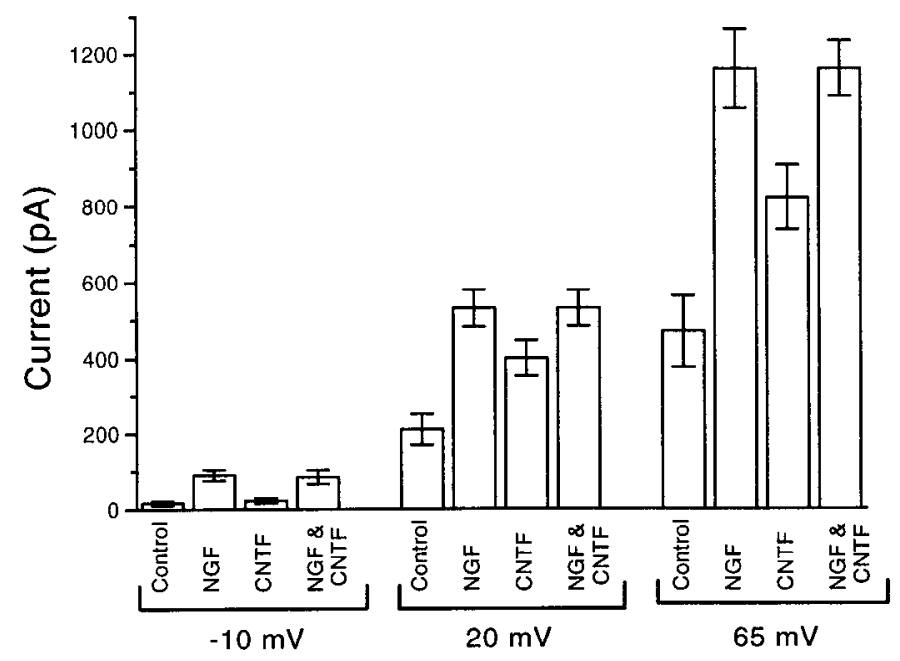

Figure 4. Differential induction of potassium currents by NGF and CNTF. Bars represent mean plateau potassium currents \pm SEM measured after depolarizing steps to $-10,+20$, and $+65 \mathrm{mV}$ (Control, $n$ $=35 ; N G F, n=36 ; C N T F, n=31 ; N G F$ and $C N T F, n=9)$. NGF treatment significantly increased potassium currents at all voltages shown, while CNTF treatment increased currents significantly only at +20 and $+65 \mathrm{mV}$.

to between -30 and $-20 \mathrm{mV}$, some $20 \mathrm{mV}$ below threshold for activation for potassium currents in CNTF-treated and control cells, and can be seen as a "bump" in current-voltage relations between -20 and $0 \mathrm{mV}$ (Fig. $3 B$ ). This extra component is apparent in the population of NGF-treated cells as a selective increase in current elicited by voltage steps to $-10 \mathrm{mV}$ (Fig. 4). Finally, this additional current component was blocked by 1 mM 4-AP (data not shown) but not by $5 \mathrm{~mm}$ TEA (Fig. 3). Potassium currents in cells treated with both CNTF and NGF did not appear to differ from those in cells treated by NGF alone $(p>0.7)$.

The TEA-insensitive current exhibited faster activation kinetics, showed no signs of inactivation over $100 \mathrm{msec}$ (Fig. $3 A$ ), and quantitatively accounted for the "bump" in current-voltage relations for NGF-treated cells. When current-voltage relationships were normalized for control, CNTF-treated, and NGFtreated cells ( $n>30$ for each group), normalized values superimposed at every voltage for control and CNTF-treated cells (Fig. 5). However, normalized current-voltage curves were different for NGF-treated cells at membrane potentials between -20 and $0 \mathrm{mV}$, confirming that the extra component in NGFtreated cells did not arise simply from larger overall currents. Furthermore, when the TEA-insensitive current component was subtracted from traces recorded from NGF-treated cells (e.g., see Fig. $6 B$ ) the normalized current-voltage relationships of the remaining currents became indistinguishable from those for CNTF-treated and control cells (Fig. 5).

The activation of potassium currents in cells of every experimental group was well fitted by a single exponential function, suggesting that the majority of the potassium current in each case could be carried by a single type of potassium channel. Moreover, time constants for activation at $+20 \mathrm{mV}$ were indistinguishable among NGF-treated cells, CNTF-treated cells, and cells treated with both NGF and CNTF; all were slightly lower than time constants measured for control cells $(p<0.05$; Fig. 6A). The voltage dependence of activation was also indistinguishable among CNTF-treated, NGF-treated, and control

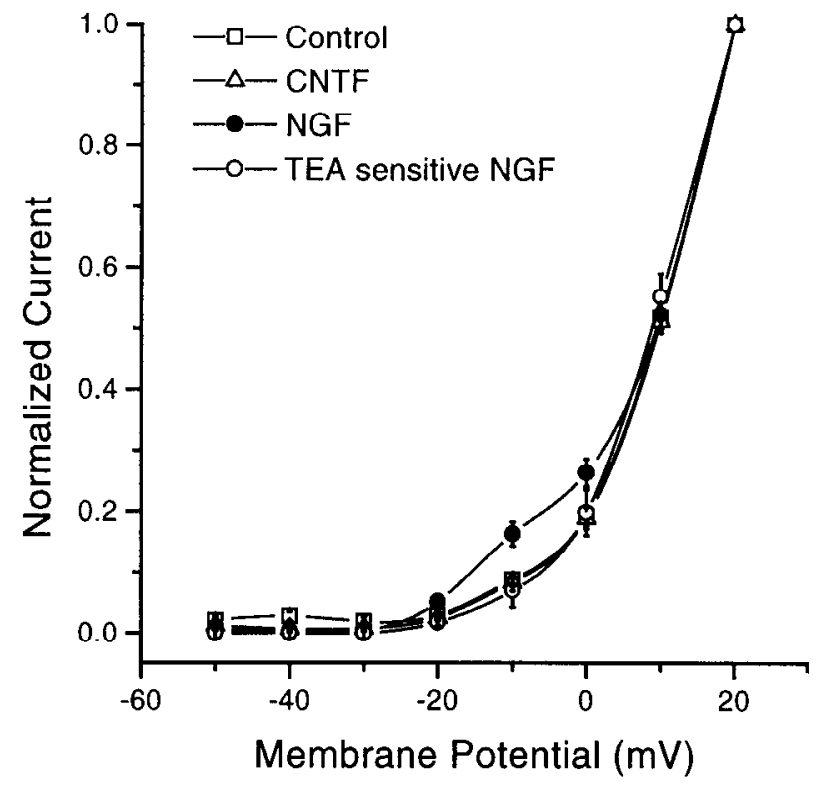

Figure 5. NGF induces an additional potassium current component. Current-voltage relations for potassium currents in control, NGF-, and CNTF-treated cells were normalized to current levels at $+20 \mathrm{mV}$; mean current levels \pm SEM were then calculated and plotted $(n>33$ for each group; symbols without error bars reflect standard errors smaller than symbol size). Normalized current-voltage relations for control and CNTF-treated cells superimpose, while that for total current in NGFtreated cells diverges between -20 and $0 \mathrm{mV}$. After subtraction of the TEA-insensitive component, the normalized current-voltage relation for NGF-treated cells also superimposes $(n=8)$, indicating that the TEA-insensitive component can quantitatively account for the "bump" in current-voltage relations for potassium currents in NGF-treated cells.

cells: activation rates increased by $e$-fold per 20.2, 20.0, and $19.1 \mathrm{mV}$, respectively (Fig. 7). Since we knew that currents in NGF-treated cells contained a small, TEA-insensitive component, we confirmed that our measurements of the time constants of activation were not significantly contaminated by measuring rise times before and after subtraction of the TEA-insensitive component (Fig. $6 B$ ). Although the activation of the TEA-insensitive current component was somewhat faster, it did not appear to contribute significantly to exponential fitting of rise times for the overall potassium current in NGF-treated cells.

\section{Single potassium channel currents}

Several potassium channel types were seen in outside-out patch recordings taken from these cells, but one channcl typc prcdominated in patches taken from cells in all experimental groups, and was absent in only two patches out of 19 analyzed in this study (Fig. $8 \mathrm{~A}$ ). This channel had a single-channel conductance of $18.6 \mathrm{pS}$, was sensitive to block by TEA, and exhibited activation rates, open durations, and a voltage dependence of activation kinetics consistent with it being a delayed-rectifier potassium channel (Hoshi and Aldrich, 1988; Paulmichl et al., 1991). Summation of multiple single-channel records yielded cumulative currents whose activation kinetics were fitted well by single exponential functions. Such cumulative currents recorded from outside-out patches taken from cells in the different experimental groups were indistinguishable in kinetics; for clarity, activation time constants measured from these patches at various potentials were pooled and plotted in Figure $8 \mathrm{~B}$. As a group, the activation kinetics of these channels exhibited simple 
Figure 6. Potassium currents in NGFand CNTF-treated cells have similar activation kinetics. $A$, Potassium currents elicited by depolarizing steps to $+20 \mathrm{mV}$ in the four experimental groups indicated were fitted by single exponentials visually followed by minimizing $\chi^{2}$ deviation. Bars represent average time constants for best fits \pm SEM (Control, $n=18 ; N G F, n=24 ; C N T F$, $n=25 ; N G F$ and $C N T F, n=9$ ). Time constants for activation were similar for potassium currents in cells treated with NGF, CNTF, and NGF + CNTF, but somewhat slower for currents in control cells. B: Top, Representative traces showing total potassium current in an NGF-treated cell $(a)$, residual current after block by 5 mM TEA $(b)$, and subtracted current $(a-b)$ representing the TEA-sensitive current component $(c)$. Best single-exponential fits are superimposed over each trace. Bottom, Measurements of activation kinetics were not altered significantly after subtraction of the TEA-insensitive component in NGF-treated cells. Bars represent average time constants for best fits \pm SEM for total, TEA-insensitive, and subtracted potassium currents as described in top for eight NGF-treated cells.
A

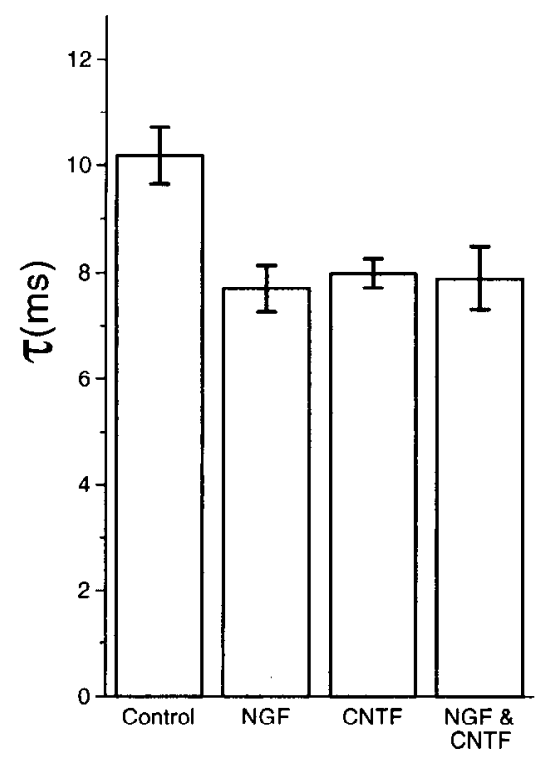

B
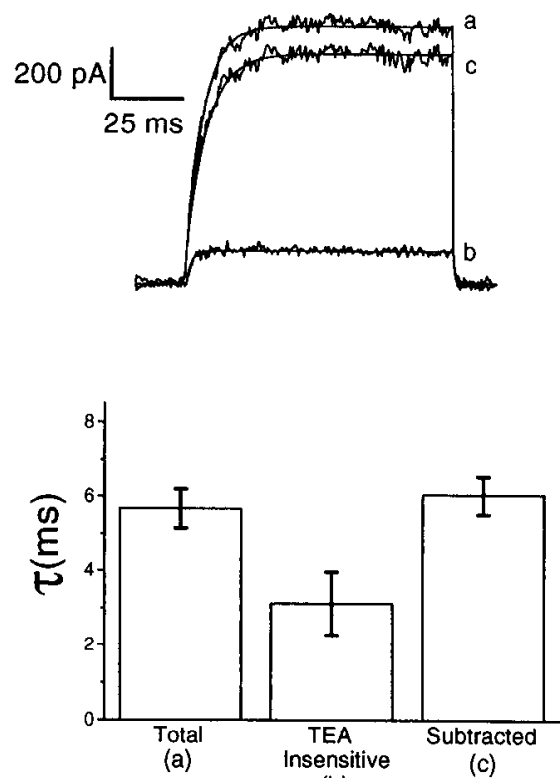

exponential dependence on voltage that was identical to that measured for whole-cell recordings ( $e$-fold per $20.0 \mathrm{mV}$; Fig. $8 B$ ). However, activation time constants were faster than thosc for whole-cell currents at every potential tested (see Discussion).

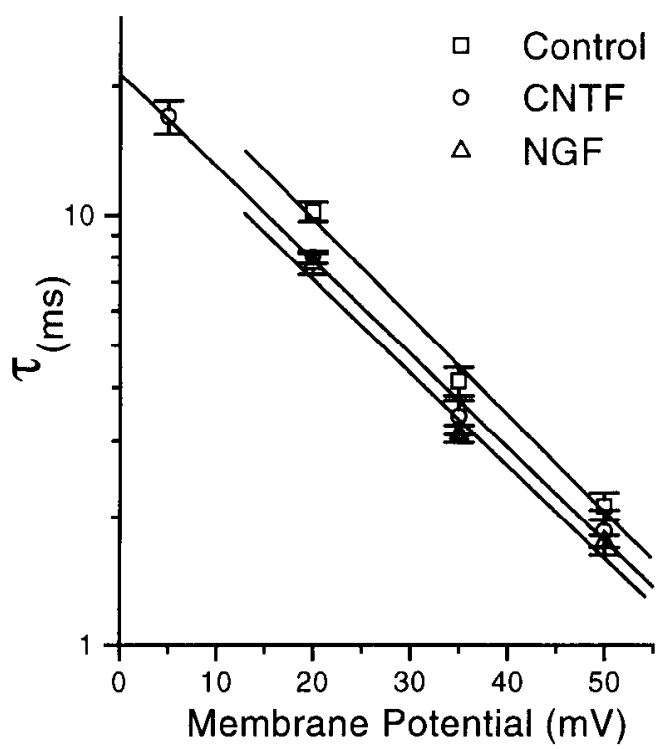

Figure 7. Voltage dependence of potassium current activation. Activation time constants for best fits to whole-cell potassium currents in control, NGF-, and CNTF-treated cells (see Fig. 6B) are plotted against membrane potential. Voltage dependencies were determined by apparent linear least-squares fits to points on the semilogarithmic plot, shown superimposed; these were $e$-fold per $19.1 \mathrm{mV}$ for control cells, $e$-fold per $20.0 \mathrm{mV}$ for NGF-treated cells, and $e$-fold per $20.2 \mathrm{mV}$ for CNTFtreated cells.

\section{Discussion}

Ncuronal cxcitability is acquired progressively during development and adjusted throughout maturity by processes that are strongly regulated by extracellular signals such as NGF (for review, see Spitzer, 1991). These signals may also include other neurotrophic factors such as the other members of the NGF family of neurotrophins and the unrelated factor ciliary neurotrophic factor (CNTF). Moreover, because neurotrophic factors and their receptors continue to be expressed in the adult and are regulated by neuronal activity (Gall and Isackson, 1989; Zafra et al., 1990; Ernfors et al., 1991; Isackson et al., 1991; Birren et al., 1992; Patterson et al., 1992), trophic interactions may be important for neural functions beyond those established during development including, perhaps, mediation of some forms of long-term plasticity (Lo, 1992). Indeed, strong support for the regulation of synaptic transmission by neurotrophic factors has been recently provided by Lohof et al. (1993), who found that spontaneous neuromuscular transmission in developing synapses was potentiated by BDNF and NT-3, but not NGF.

One approach toward understanding the nature of these neurotrophic interactions both in development and in maturity is to determine how molecular elements of excitability and synaptic transmission such as ion channels are regulated by different neurotrophic factor systems. In particular, different neurotrophic factor families such as those typified by NGF and CNTF might be expected to have both parallel and opposing effects on neuronal excitability. SK-N-SH cells, a human neuroblastoma of presumed sympathetic origin that has been used as a model for neuronal differentiation, provide an ideal experimental system in which to study the effects of NGF and CNTF (Biedler et al., 1973; Squinto et al., 1990). Although this cell line has been shown to respond to both factors, the functional importance of neurotrophic action on SK-N-SH cells remains largely 
A
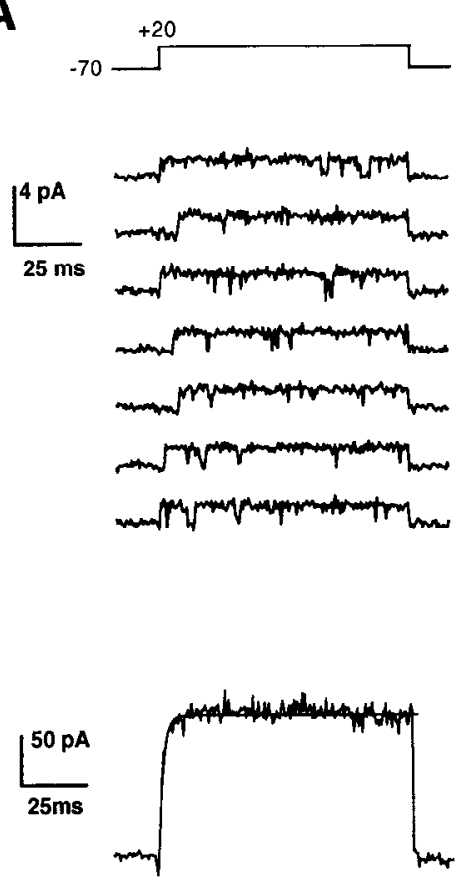

B

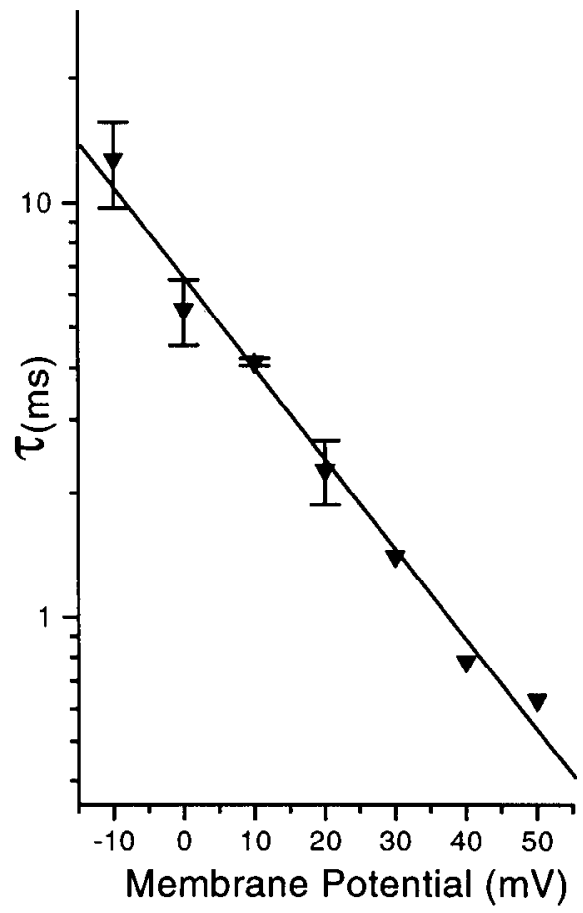

Figure 8. A delayed-rectifier type potassium channel that shows voltage dependence of activation kinetics identical to that for whole-cell potassium currents in control, NGF-, and CNTFtreated cells. $A$ : $T O P$, Representative single-channel currents from an outside-out patch taken from an NGFtreated cell. Channel activity was elicited by a depolarizing step to $+20 \mathrm{mV}$ from a holding potential of $-70 \mathrm{mV}$; data were recorded at a $500 \mu \mathrm{sec}$ sample interval and filtered at $2 \mathrm{kHz}$. Bottom, Such currents were summed, and the resulting cumulative current fitted with a single exponential, shown superimposed. $B, \Lambda$ verage time constants \pm SEM for best exponential fits plotted against voltage. Activation time constants were pooled from best fits to cumulative currents from six outside-out patches taken from cells in different experimental groups (see Results); points at $+30,+40$, and $+50 \mathrm{mV}$ were taken from single patches. Voltage dependence of activation was $e$-fold per 20.0 $\mathrm{mV}$. uncharacterized. PC12 cells, on the other hand, have been used extensively as a model system in which to elucidate the biological actions of NGF (Greene and Tischler, 1976; for review, see Halegoua et al., 1991), including its induction of voltage-gated sodium and calcium channel expression (see, e.g., Garber et al., 1989; Pollack et al., 1990; Usowicz et al., 1990). However, PC12 cells are not responsive to other neurotrophic factors such as CNTF.

We have shown in the present study that SK-N-SH cells have markedly different responses to NGF and CNTF in terms of the voltage-gated ion channels they regulate. While NGF increased both sodium and calcium current levels in SK-N-SH cells, CNTF did not. Both NGF and CNTF, however, increased levels of a delayed-rectifier type potassium current; additionally, NGF-treated cells also exhibited a second, smaller current component that was TEA insensitive. The delayed-rectifier type current may represent a common potassium current that is expressed basally in untreated SK-N-SH cells, induced by CNTF, and the principal target of induction by NGF. This possibility is supported by the following: (1) activation kinetics of wholecell potassium currents from all groups were fitted well by single exponential functions and were indistinguishable both in rates and voltage dependence, and (2) treatment with both NGF and CNTF did not induce expression of potassium currents to levels higher than those induced by NGF alone. Thus, our experiments are consistent with the idea that CNTF and NGF signal transduction pathways converge on the same target potassium current, but further experiments using single-channel recording and molecular approaches will be necessary to confirm this possibility.

In this context, we studied the single potassium channels that are expressed in SK-N-SH cells, both before and after treatment with NGF and CNTF. Since macroscopic potassium currents in all groups were dominated by an apparently common de- layed-rectifier current with indistinguishable voltage dependence and kinetics, it would be expected that patches would similarly be dominated by a single delayed-rectifier type potassium channel. While we observed several distinct voltage-gated potassium channels in outside-out patches taken from these cells, a single type of potassium channel with the characteristics of delayed-rectifier potassium channels was, in fact, observed in nearly all patches from all experimental groups (Fig. 8). This channel exhibited a voltage dependence of activation that was identical to those for whole-cell currents, and is thus a candidate for the potassium channel species regulated by NGF and CNTF and provides further evidence that the same ion channel species is being regulated by both factors. However, the kinetics of activation of this channel were somewhat faster than those for macroscopic currents at every voltage tested (compare Figs. 7, $8 B$ ). Further study will be required to determine whether this discrepancy arises as a consequence of patch excision, or that this channel is not the principal one underlying the regulated macroscopic potassium currents.

The possible convergence of NGF and CNTF signaling pathways on the regulation of a single, delayed-rectifier potassium channel is of particular interest because the initial steps of signal transduction for the two factors are distinct. Most notably, the receptor complex for NGF contains a receptor tyrosine kinase (the $t r k$ receptor; Chao, 1992a,b), while the receptor for CNTF acts through cytoplasmic tyrosine kinases including JAK (Stahl and Yancopoulos, 1993; Stahl et al., 1994). Overlap in these signaling pathways could well occur at subsequent steps; for example, both the NGF and CNTF transduction pathways involve activation of $\mathrm{p} 21$ ras (Borasio et al., 1993).

The current-voltage relation for the additional potassium current component induced by NGF and the insensitivity of this current to TEA block were consistent with it being carried by a small-conductance $\mathrm{Ca}^{2+}$-activated potassium channel (Hille, 
1992). Our experiments did not directly address whether this current was specifically induced by NGF or that its expression was latent and only activated in NGF-treated cells because of their greatly increased calcium currents. Although not measurable by whole-cell recording, some residual calcium entry may still have occurred in the solutions we used for potassium current recording (low external calcium, EGTA in the pipette); this residual calcium current should be larger in NGF-treated cells. In support of this, the TEA-insensitive current was blocked by extracellular addition of $1 \mathrm{~mm}$ cobalt (which should block calclum currents) and was inactivated by a holding potential of $-30 \mathrm{mV}$ (which should inactivate LVA calcium channels).

In PC12 cells, the induction of sodium currents by NGF has been directly tied to transcriptional regulation of the brain type II sodium channel gene (Cooperman et al., 1987; Mandel et al., 1988; Kraner et al., 1992), and occurs over the time course of 3-5 d (see, e.g., Garber et al., 1989; Pollack et al., 1990; Lesser and Lo, unpublished observations). As the induction by NGF and CNTF of sodium, calcium, and potassium currents in SK$\mathrm{N}$-SH cells occurred with a similar time course, we surmise that these events, by analogy, also arise from changes in gene expression. Consistent with this, acute application of NGF and CNTF to SK-N-SH cells under perforated-patch recording had no significant effect on voltage-gated ionic current levels over the time course of $\sim 1 \mathrm{hr}(n=15)$. However, our data do not exclude the possibility that the changes we observe reflect longterm posttranslational modifications of existing channel proteins.

Regardless of their molecular basis, similar changes in neuronal ionic currents in vivo would have profound effects on neuronal activity. The differential regulation of sodium, calcium, and potassium currents by NGF and CNTF is particularly interesting as such regulation in neurons would greatly affect action potential shape, firing frequency, and synaptic transmission in both parallel and opposing ways (see, e.g., Thompson and Aldrich, 1980; Chalazonitis et al., 1987; Augustine, 1990; Hille, 1992; Lockery and Spitzer, 1992). Increased potassium current densities have been observed during early development of hippocampal granule cells (Beck et al., 1992), Xenopus spinal neurons (Desarmenien et al., 1993), as well as in developing sympathetic neurons (Nerbonne and Gurney, 1989; McFarlane and Cooper, 1992). Interestingly, relatively high expression levels of CNTF, NGF, and their receptors have been localized in these areas (Maisonpierre et al., 1990; Squinto et al., 1990; Dobrea et al., 1992). The somewhat faster activation kinetics of the delayed-rectifier type potassium current in NGF- and CNTF-trcatcd cells (Fig. 6) is, in fact, strikingly similar to that observed for delayed-rectifier currents during the maturation of Xenopus spinal neurons, which depends on extracellular calcium and protein kinase C (Desarmenien and Spitzer, 1991).

McFarlane and Cooper (1993) have investigated the importance of factors produced by non-neuronal cells that may be involved in the regulation of potassium currents in developing sympathetic neurons from superior cervical ganglia (SCG); they have shown that CNTF and non-neuronal cell-conditioned medium have effects on the regulation of potassium currents in primary-cultured SCG neurons. However, because their culture medium also contained NGF, their results appear to suggest that the addition of NGF and CNTF in combination has qualitatively different effects on potassium current regulation compared to the addition of NGF alone. In contrast, our experiments show that the addition of both NGF and CNTF to SK-N-SH cells led to increases in potassium currents that were indistinguishable from those resulting from addition of NGF alone. This disparity underscores the importance of cellular context in the nature of responses to inductive signals. For example, in our hands NGF induces sodium and calcium currents but not potassium currents in $\mathrm{PCl} 2$ cells, while we have shown that all three classes of voltage-gated ion channels are regulated by NGF in SK-N-SH cells.

\section{References}

Augustine GJ (1990) Regulation of transmitter release at the squid giant synapse by presynaptic delayed rectifier potassium current. J Physiol (Lond) 431:343-364.

Bazan JF (1991) Neuropoietic cytokines in the hematopoietic fold. Neuron 7:197-208.

Beck H, Ficker E, Heinemann U (1992) Properties of two voltageactivated potassium currents in acutely isolated juvenile rat dentate gyrus granule cells. J Neurophysiol 68:2086-2099.

Biedler J, Helson L, Spengler B (1973) Morphology and growth, tumorigenicity, and cytogenetics of human neuroblastoma cells in continuous culture. Cancer Res 33:2643-2652.

Biedler JL, Roffler-Tarlov S, Schachner M, Freedman LS (1978) Multiple neurotransmitter synthesis by human neuroblastoma lines and clones. Cancer Res 38:3751-3757.

Birren SJ, Verdi JM, Anderson DJ (1992) Membrane depolarization induces p140 rik and NGF responsiveness, but not p $75^{\mathrm{LNGFR}}$, in MAH cells. Science 257:395-397.

Byerly L, Hagiwara S (1982) Calcium currents in internally perfused nerve cell bodies of Limnea stagnalis. J Physiol (Lond) 322:503-528.

Chalazonitis A, Peterson E, Crain S (1987) Nerve growth factor regulates the action potential duration of mature sensory neurons. Proc Natl Acad Sci USA 84:289-293.

Chao MV (1992a) Growth factor signaling: where is the specificity? Cell 68:995-997.

Chao MV (1992b) Neurotrophin receptors: a window into neuronal differentiation. Neuron 9:583-593.

Cooperman SS, Grubman SA, Barchi RL, Goodman RH, Mandel G (1987) Modulation of sodium-channel mRNA levels in rat skeletal muscle. Proc Natl Acad Sci USA 84:8721-8725.

Davis S, Yancopoulos G (1993) The molecular biology of the CNTF receptor. Curr Opin Neurobiol 3:20-24.

Davis S, Aldrich TH, Valenzuela DM, Wong V, Furth ME, Squinto SP, Yancopoulos GD (1991) The receptor for ciliary neurotrophic factor. Science 253:59-63.

Davis S, Aldrich T, Ip N, Stahl N, Scherer S, Farruggella T, DiStefano P, Curtis R, Panayotatos N, Gascan H, Chevalier S, Yancopoulos G (1993a) Released form of CNTF receptor $\alpha$ component as a soluble mediator of CNTF responses. Science 259:1736-1739.

Davis S, Aldrich T, Stahl N, Pan L, Taga T, Kishimoto T, Ip N, Yancopoulos G (1993b) LIF $\beta$ and gp130 as heterodimerizing signal transducers of the tripartite CNTF receptor. Science 260:1805-1808.

Desarmenien M, Spitzer N (1991) Role of calcium and protein kinase $\mathrm{C}$ in development of the delayed-rectifier potassium current in Xenopus spinal neurons. Neuron 7:797-805.

Desarmenien M, Clendening B, Spitzer N (1993) In vivo development of voltage-dependent ionic currents in embryonic spinal neurons. J Neurosci 13:2575-2581.

Dobrea G, Unnerstall, Rao M (1992) The expression of CNTF message and immunoreactivity in the central and peripheral nervous system of the rat. Dev Brain Res 66:209-219.

Ernfors P, Bengzon J, Kokaia Z, Persson H, Lindvall O (1991) Increased levels of messenger RNAs for neurotrophic factors in the brain during kindling epileptogenesis. Neuron 7:165-176.

Gall CM, Isackson PJ (1989) Limbic seizures increase neuronal production of messenger RNA for nerve growth factor. Science 245:758761 .

Garber S, Hoshi T, Aldrich RW (1989) Regulation of ionic current in pheochromocytoma cells by nerve growth factor and dexamethasone. J Neurosci 9:3976-3987.

Greene LA, Tischler AS (1976) Establishment of a noradrenergic clonal line of rat adrenal pheochromocytoma cells which respond to nerve growth factor. Proc Natl Acad Sci USA 73:2424-2428.

Halegoua S, Armstrong R, Kremer N (1991) Dissecting the mode of 
action of a neuronal growth factor. In: Current topics in microbiology and immunology, Vol 165, Neuronal growth factors (Bothwell M, ed), pp 119-170. Berlin: Springer.

Hall AK, Rao MS (1992) Cytokines and neurokines: related ligands and related receptors. Trends Neurosci 15:35-37.

Hamill O, Marty A, Neher E, Sakmann B, Sigworth F (1981) Improved patch-clamp techniques for high-resolution current recording from cells and cell-free membrane patches. Pfluegers Arch 391:85-100.

Hefti F, Denton T, Knusel B, Lapchak P (1993) Neurotrophic factors: what are they and what are they doing? In: Neurotrophic factors (Loughlin SE, Fallon JH, eds), pp 25-49. New York: Academic.

Hille B (1992) Ionic channels of excitable membranes. Sunderland, MA: Sinauer.

Horn R, Marty A (1988) Muscarinic activation of ionic currents measured by a new whole-cell recording method. J Gen Physiol 92:145159.

Hoshi T, Aldrich R (1988) Voltage-dependent $\mathrm{K}^{+}$currents and underlying $\mathrm{K}^{+}$channels in pheochromocytoma cells. J Gen Physiol 91: 73-106.

In NY, Yancopoulos GD (1992) CNTF and its receptor complex. Prog Growth Factor Res 4:139-155.

Ip NY, Nye SH, Boulton TG, Davis S, Taga T, Li Y, Birren SJ, Yasukawa K, Kishimoto T, Anderson DJ, Stahl N, Yancopoulos GD (1992) CNTF and LIF act on neuronal cells via shared signaling pathways that involve the IL-6 signal transducing receptor gp130. Cell 69:1121-1132.

Ip NY, McClain J, Barrezueta NX, Aldrich TH, Pan L, Li Y, Wiegand SJ, Friedman B, Davis S, Yancopoulos GD (1993) The $\alpha$ component of the CNTF receptor is required for signaling and defines potential targets in the adult and during development. Neuron 10:89-102.

Isackson PJ, Huntsman MM, Murray KD, Gall CM (1991) BDNF mRNA expression is increased in adult rat forebrain after limbic seizures: temporal patterns of induction distinct from NGF. Neuron 6:937-948.

Kraner SD, Chong JA, Tay H-J, Mandel G (1992) Silencing the type II sodium channel gene: a model for neural-specific gene regulation. Neuron 9:37-44.

Lindsay RM, Wiegand SJ, Altar A, DiStefano PS (1994) Neurotrophic factors: from molecule to man. Trends Neurosci 17:182-190.

Lo DC (1992) Signal transduction and regulation of neurotrophins. Curr Opin Neurobiol 2:336-340.

Lockery S, Spitzer N (1992) Reconstruction of action potential development from whole-cell currents of differentiating spinal neurons. J Neurosci 12:2268-2287.

Lohof A, Ip N, Poo M-m (1993) Potentiation of developing neuromuscular synapses by the neurotrophins NT-3 and BDNF. Nature 363:350-353.

Maisonpierre PC, Belluscio L, Friedman B, Alderson RF, Wiegand SJ, Furth ME, Lindsay RM, Yancopoulos GD (1990) NT-3, BDNF, and NGF in the developing rat nervous system: parallel as well as reciprocal patterns of expression. Neuron 5:501-509.

Mandel G, Cooperman SS, Maue RA, Goodman RH, Brehm P (1988) Selective induction of brain type II $\mathrm{Na}^{+}$channels by nerve growth factor. Proc Natl Acad Sci USA 85:924-928.

Manthorpe M, Louis J-C, Hagg T, Varon S (1993) Ciliary neurotrophic factor. In: Neurotrophic factors (Loughlin SE, Fallon JH, eds), pp 443-473. New York: Academic.

McFarlane S, Cooper E (1992) Postnatal development of voltage-gated
K currents on rat sympathetic neurons. J Neurophysiol 67:12911300.

McFarlane S, Cooper E (1993) Extrinsic factors influence the expression of voltage-gated $\mathrm{K}$ currents on neonatal rat sympathetic neurons. J Neurosci 13:2591-2600.

Morton A, Hammond C, Mason W, Henderson G (1992) Characterization of the L- and N-type calcium channels in differentiated SHSY5Y neuroblastoma cells: calcium imaging and single channel recording. Mol Brain Res 13:52-61.

Nerbonne J, Gurney A (1989) Development of excitable membrane properties in mammalian sympathetic neurons. J Neurosci 9:33723386.

Pahlman S, Mamaeva S, Meyerson G, Mattsson ME, Bjelfman C, Ortoft E, Hammerling U (1990) Human neuroblastoma cells in culture: a model for neuronal cell differentiation. Act Physiol Scand 592:2537.

Patterson P, Nawa H (1993) Neuronal differentiation factors/cytokines and synaptic plasticity. Cell 72/Neuron 10[Suppl]:123-137.

Patterson SL, Grover LM, Schwartzkroin PA, Bothwell M (1992) Neurotrophin expression in rat hippocampal slices: a stimulus paradigm inducing LTP in CA1 evokes increases in BDNF and NT-3 mRNAs. Neuron 9:1081-1088.

Paulmichl M, Nasmith P, Hellmiss R, Reed K, Boyle W, Nerbonne J Peralta E, Clapham D (1991) Cloning and expression of a rat cardiac delayed rectifier potassium channel. Proc Natl Acad Sci USA 88: 7892-7895.

Pollock JD, Krempin M, Rudy B (1990) Differential effects of NGF, FGF, EGF, cAMP, and dexamethasone on neurite outgrowth and sodium channel expression in PCl 2 cells. J Neurosci 10:2626-2637.

Saadat S, Sendtner M, Rohrer H (1989) Ciliary neurotrophic factor induces cholinergic differentiation of rat sympathetic neurons in culture. J Cell Biol 108:1807-1816.

Spitzer N (1991) A developmental handshake: neuronal control of ionic currents and their control of neuronal differentiation. J Neurobiol 22:659-673.

Squinto SP, Aldrich TH, Lindsay RM, Morrisey DM, Panayotatos N, Bianco SM, Furth ME, Yancopoulos GD (1990) Identification of functional receptors of $\mathrm{CNTF}$ on neuronal cell lines and primary neurons. Neuron 5:757-766.

Stahl N, Yancopoulos G (1993) The alphas, betas, and kinases of cytokine receptor complexes. Cell 74:587-590.

Stahl N, Boulton T, Farruggella T, Ip N, Davis S, Witthuhn B, Quelle F, Silvennoinen $O$, Barbieri G, Pellegrini S, Ihle J, Yancopoulos G (1994) Association and activation of Jak-Tyk kinases by CNTF-LIFOSM-IL-6 $\beta$ receptor components. Science 263:92-95.

Stockli KA, Lottspeich F, Sendtner M, Masiakowski P, Carroll P, Gotz $R$, Lindholm D, Thoenen $H$ (1989) Molecular cloning, expression and regional distribution of rat CNTF. Nature 342:920-923.

Thompson H, Aldrich R (1980) Membrane potassium channels. In: The cell surface and neuronal function (Cotman C, Poste G, Nicolson G, eds), pp 49-85. New York: Elsevier.

Usowicz MM, Porzig H, Becker C, Reuter H (1990) Differential expression by nerve growth factor of two types of $\mathrm{Ca}^{2+}$ channels in rat pheochromocyloma cell lines. J Physiol (Lond) 426:95-116.

Zafra F, Hengerer B, Leibrock J, Thoenen H, Lindholm D (1990) Activity dependent regulation of BDNF and NGF mRNAs in the rat hippocampus is mediated by non-NMDA glutamate receptors. $\mathrm{EMBO}$ J 9:3545-3550. 